Original Article

\title{
MOLECULAR DOCKING OF SELECTED BIOACTIVE COMPOUNDS FROM AZADIRACHTA INDICA FOR THE INHIBITION OF COVID19 PROTEASE
}

\author{
S. FEBINA BERNICE SHARON \\ Department of Food Science and Nutrition, Sarah Tucker College, Tirunelveli, Tamil Nadu \\ Email: febina.623@gmail.com
}

Received: 26 Jun 2020, Revised and Accepted: 28 Jul 2020

\begin{abstract}
Objective: COVID-19 caused by novel SARS-coronavirus 2 belonging to family Coronaviridae, is a global public health emergency infecting many people all around the world, especially in India with more than 2,98,000 cases. Hence there is a need for a novel drug that counters SARS-CoV2 is the prime requirement at this time.

Methods: The present study aimed to assess bioactive compounds found in Azadirachta indica as a potential inhibitor of COVID-19 Mpr ${ }^{\circ}(6$ Y2E, 6LU7, and 2GTB) by Autodock 4.2, with the Lamarckian Genetic Algorithm. COVID-19 Mpr ${ }^{\circ}$ was docked with thirteen bioactive compounds, and docking was analyzed by Autodock 4.2 and Pymol. Nelfinavir and Saquinavir were used as positive standards for comparison.

Results: Azadirachtanin, Azadirachtol, and Salannolide, were left out because of the violation of Lipinski's rule. The binding energies obtained from the docking of 6Y2E with a native ligand, Azadiradione, Beta-sitosterol, Epiazadiradione, Epoxyazadiradione, Kaempferol, Meldenin, Myricetin, Nimbaflavone, Nimbinene, Nimbione, Nimbocinolide, Quercitrin, Vepnin, Saquinavir, and Nelfinavir were-7.32,-6.63,-6.69,-7.52,-5.27,-4.54,-6.07,-4.19,-5.02,-5.58,-6.23,-4.71, $-3.72,-6.4,-7.14$ and $-4.67 \mathrm{kcal} / \mathrm{mol}$ respectively. The binding energies obtained from the docking of $6 \mathrm{LU} 7$ with the native ligand, Azadiradione, Nimbione, Vepnin, and Saquinavir were-6.14,-6.48,-6.79 and-6.49 kcal/mol correspondingly. The binding energies obtained from the docking of 2GTB with the native ligand, Azadiradione, Epiazadiradione, Epoxyazadiradione, Kaempferol, Meldenin, Myricetin, Nimbaflavone, Nimbione, Nimbocinolide, Quercitrin, Vepnin, Saquinavir, and Nelfinavir were-6.96,-7.13,-6.69,-5.22,-6.44,-5.06,-5.93,-6.66,-5.3,-5.63,-7.11,-6.89 and-5.42kcal/mol, respectively.
\end{abstract}

Conclusion: Azadiradione, Epiazadiradione, Nimbione, and Vepnin seemed to have the greatest potential to act as COVID-19 protease inhibitors. However, further research is necessary to explore their prospective medicinal use in vitro and in vivo conditions.

Keywords: COVID-19 Mro, 6Y2E, 6LU7 Autodock, Azadirachta indica and Saquinavir

(C) 2020 The Authors. Published by Innovare Academic Sciences Pvt Ltd. This is an open access article under the CC BY license (http://creativecommons.org/licenses/by/4.0/) DOI: http://dx.doi.org/10.22159/ijpps.2020v12i9.38875. Journal homepage: https://innovareacademics.in/journals/index.php/ijpps.

Speedy peer review was done as the subject of the manuscript was related with pandemic

\section{INTRODUCTION}

The Coronavirus disease 19 (COVID 19) is a highly transmitted and pathogenic viral infection caused by the severe acute respiratory syndrome coronavirus 2 (SARS-CoV-2), which started emerging in Wuhan, China and spread around the world $[1,2]$. With an exemption of Antarctica, it is vigorously transmitted from Wuhan city to nearly every country in the world [3]. According to the World Health Organization (WHO) on 24 June 2020 around 91,29,146 cases of persons infected worldwide by COVID-19 out of which 4,73,797 death in 216 countries. Since COVID-19 is quickly spreading, the WHO has declared it as a pandemic disease [4]. Common symptoms of the corona virus-infected person have respiratory symptoms, fever, cough, shortness of breath, and dyspnea. In severe cases, an infection can cause pneumonia, severe acute respiratory syndrome, kidney failure, and even death $[5,6]$ Presently there is no specific treatment for COVID 19.

Coronaviruses are enveloped viruses with a positive RNA genome, belonging to the Coronaviridae family of the order Nidovirales, which are divided into four genera, namely $\alpha, \beta, \gamma$, and $\delta$ [5]. The SARS-CoV-2 belongs to the $\beta$ genus. Coronavirus contains at least four structural proteins: Spike (S) protein, envelope (E) protein, membrane (M) protein, and nucleocapsid $(\mathrm{N})$ protein [7]. Among that, Spike helps in host attachment and membrane fusion during the infection of the virus Therefore, Spike determines to some extent of the host range [5]. The main protease (Mpro)/chymotrypsin-like protease (3CLpro) from COVID-19, which has been successfully crystallized, structured, and repositioned in the Protein Data Bank and this protease represents a potential target for the inhibition of Corona Virus replication [8].

Azadirachta indica (Neem) is a member of the Meliaceae family and its role in health-promoting outcome is recognized because of its antioxidant property and various other antimicrobial properties. It has been widely used in Chinese, Ayurvedic, and Unani medicines worldwide, especially in the Indian subcontinent in the treatment and prevention of various diseases [9]. Azadirachta indica has more than 140 chemically active compounds isolated from its different parts, including i.e. seeds, roots, flowers, fruits, leaves, and bark and are used traditionally for curing many diseases. These active compounds have been identified as anti-mutagenic, anti-inflammatory, anti-oxidant, antiulcer, anti-hyperglycaemic, immune-modulator, anti-carcinogenic, and anti-viral drugs [10]. Since COVID-19 is the highest outbreak in almost al nations, novel methodologies of drug strategy and discovery can be exploited as a promising tool for finding various therapeutic drug agents.

In the present study, we observe the binding affinity of 16 ligands, which are present in Azadirachta indica for COVID-19 6LU7, 6Y2E proteases, and 2GTB. The main purpose of this study is to make use of recognized natural products to be used to strengthen defences against coronavirus by developing drugs based on natural products.

\section{MATERIALS AND METHODS}

Macromolecule (protein) and ligand

The COVID-19 Mpro (PDB ID: 6LU7, 6Y2E, 2GTB) structures of the main protease were obtained from the Protein Data Bank (https://www.rcsb.org/) in. pdb format. The 6LU7 protein contains two chains, A and B, which form a homodimer. Chain A alone was taken for macromolecule preparation. Drug-like properties were calculated using Lipinski's rule of five, which suggested that molecules with poor permeation and oral absorption have molecular weights $>500, C \log P>5$, more than 5 Hydrogen-bond donors, more than 10 acceptor groups, more than 10 rotatable bonds, and Molar refractivity was not in the range between 40 and $130[8,11,12]$. Adherence to Lipinski's rule of five was calculated using SWISSADME (http://www.swissadme.ch/). 
Table 1: Properties of ligand molecules from Azadirachta indica

\begin{tabular}{|c|c|c|c|c|}
\hline \multirow[t]{2}{*}{ S. No. } & \multirow[t]{2}{*}{ Name of the ligand } & \multirow[t]{2}{*}{ Molecular formula } & \multicolumn{2}{|l|}{ Lipinski's rule of five } \\
\hline & & & Properties & Value \\
\hline \multirow[t]{7}{*}{1} & Azadirachtanin & $\mathrm{C}_{32} \mathrm{H}_{40} \mathrm{O}_{11}$ & Molecular weight & $600.65 \mathrm{~g} / \mathrm{mol}$ \\
\hline & & & $\log P$ & 3.82 \\
\hline & & & $\mathrm{H}$-bond donor & 2 \\
\hline & & & H-bond acceptor & 11 \\
\hline & & & Molar refractivity & 148.84 \\
\hline & & & Number of rotatable bonds & 7 \\
\hline & & & Violations & 3 \\
\hline \multirow[t]{7}{*}{2} & Azadirachtol & $\mathrm{C}_{28} \mathrm{H}_{36} \mathrm{O}_{13}$ & Molecular weight & $580.58 \mathrm{~g} / \mathrm{mol}$ \\
\hline & & & $\log P$ & 2.81 \\
\hline & & & H-bond donor & 4 \\
\hline & & & H-bond acceptor & 13 \\
\hline & & & Molar refractivity & 131.30 \\
\hline & & & Number of rotatable bonds & 5 \\
\hline & & & Violations & 3 \\
\hline \multirow[t]{7}{*}{3} & Azadiradione & $\mathrm{C}_{28} \mathrm{H}_{34} \mathrm{O}_{5}$ & Molecular weight & $450.57 \mathrm{~g} / \mathrm{mol}$ \\
\hline & & & $\log \mathrm{P}$ & 3.18 \\
\hline & & & $\mathrm{H}$-bond donor & 0 \\
\hline & & & H-bond acceptor & 5 \\
\hline & & & Molar refractivity & 125.48 \\
\hline & & & Number of rotatable bonds & 3 \\
\hline & & & Violations & 0 \\
\hline \multirow[t]{7}{*}{4} & Beta-sitosterol & $\mathrm{C}_{29} \mathrm{H}_{50} \mathrm{O}$ & Molecular weight & $414.71 \mathrm{~g} / \mathrm{mol}$ \\
\hline & & & $\log P$ & 5.05 \\
\hline & & & H-bond donor & 1 \\
\hline & & & H-bond acceptor & 1 \\
\hline & & & Molar refractivity & 133.23 \\
\hline & & & Number of rotatable bonds & 6 \\
\hline & & & Violations & 2 \\
\hline \multirow[t]{7}{*}{5} & Epiazadiradione & $\mathrm{C}_{28} \mathrm{H}_{34} \mathrm{O}_{5}$ & Molecular weight & $450.57 \mathrm{~g} / \mathrm{mol}$ \\
\hline & & & $\log \mathrm{P}$ & 3.11 \\
\hline & & & H-bond donor & 0 \\
\hline & & & H-bond acceptor & 5 \\
\hline & & & Molar refractivity & 125.48 \\
\hline & & & Number of rotatable bonds & 3 \\
\hline & & & Violations & 0 \\
\hline \multirow[t]{7}{*}{6} & Epoxyazadiradione & $\mathrm{C}_{28} \mathrm{H}_{34} \mathrm{O}_{6}$ & Molecular weight & $466.57 \mathrm{~g} / \mathrm{mol}$ \\
\hline & & & $\log P$ & 3.32 \\
\hline & & & H-bond donor & 0 \\
\hline & & & H-bond acceptor & 6 \\
\hline & & & Molar refractivity & 124.96 \\
\hline & & & Number of rotatable bonds & 3 \\
\hline & & & Violations & 0 \\
\hline \multirow[t]{7}{*}{7} & Kaempferol & $\mathrm{C}_{15} \mathrm{H}_{10} \mathrm{O}_{6}$ & Molecular weight & $286.24 \mathrm{~g} / \mathrm{mol}$ \\
\hline & & & $\log P$ & 1.70 \\
\hline & & & H-bond donor & 4 \\
\hline & & & H-bond acceptor & 6 \\
\hline & & & Molar refractivity & 76.01 \\
\hline & & & Number of rotatable bonds & 1 \\
\hline & & & Violations & 0 \\
\hline 8 & Meldenin & $\mathrm{C}_{28} \mathrm{H}_{38} \mathrm{O}_{5}$ & Molecular weight & $454.60 \mathrm{~g} / \mathrm{mol}$ \\
\hline & & & $\log P$ & 3.43 \\
\hline & & & $\mathrm{H}$-bond donor & 1 \\
\hline & & & H-bond acceptor & 5 \\
\hline & & & Molar refractivity & 126.91 \\
\hline & & & Number of rotatable bonds & 3 \\
\hline & & & Violations & 0 \\
\hline 9 & Myricetin & $\mathrm{C}_{15} \mathrm{H}_{10} \mathrm{O}_{8}$ & Molecular weight & $318.24 \mathrm{~g} / \mathrm{mol}$ \\
\hline & & & $\log \mathrm{P}$ & 1.08 \\
\hline & & & H-bond donor & 6 \\
\hline & & & $\mathrm{H}$-bond acceptor & 8 \\
\hline & & & Molar refractivity & 80.06 \\
\hline & & & Number of rotatable bonds & 1 \\
\hline & & & Violations & 0 \\
\hline 10 & Nimbaflavone & $\mathrm{C}_{26} \mathrm{H}_{30} \mathrm{O}_{5}$ & Molecular weight & $422.51 \mathrm{~g} / \mathrm{mol}$ \\
\hline & & & $\log P$ & 4.36 \\
\hline & & & H-bond donor & 2 \\
\hline & & & H-bond acceptor & 5 \\
\hline & & & Molar refractivity & 123.48 \\
\hline & & & Number of rotatable bonds & 6 \\
\hline & & & Violations & 0 \\
\hline
\end{tabular}




\begin{tabular}{|c|c|c|c|c|}
\hline \multirow[t]{7}{*}{11} & Nimbinene & $\mathrm{C}_{28} \mathrm{H}_{34} \mathrm{O}_{7}$ & Molecular weight & $482.57 \mathrm{~g} / \mathrm{mol}$ \\
\hline & & & $\log P$ & 3.68 \\
\hline & & & H-bond donor & 0 \\
\hline & & & H-bond acceptor & 7 \\
\hline & & & Molar refractivity & 128.17 \\
\hline & & & Number of rotatable bonds & 6 \\
\hline & & & Violations & 0 \\
\hline \multirow[t]{7}{*}{12} & Nimbione & $\mathrm{C}_{18} \mathrm{H}_{22} \mathrm{O}_{3}$ & Molecular weight & $286.37 \mathrm{~g} / \mathrm{mol}$ \\
\hline & & & $\log P$ & 2.24 \\
\hline & & & H-bond donor & 1 \\
\hline & & & H-bond acceptor & 3 \\
\hline & & & Molar refractivity & 82.64 \\
\hline & & & Number of rotatable bonds & 0 \\
\hline & & & Violations & 0 \\
\hline \multirow[t]{7}{*}{13} & Nimbocinolide & $\mathrm{C}_{32} \mathrm{H}_{42} \mathrm{O}_{10}$ & Molecular weight & $586.67 \mathrm{~g} / \mathrm{mol}$ \\
\hline & & & $\log \mathrm{P}$ & 2.84 \\
\hline & & & H-bond donor & 3 \\
\hline & & & H-bond acceptor & 10 \\
\hline & & & Molar refractivity & 150.48 \\
\hline & & & Number of rotatable bonds & 6 \\
\hline & & & Violations & 2 \\
\hline \multirow[t]{7}{*}{14} & Quercitrin & $\mathrm{C}_{21} \mathrm{H}_{20} \mathrm{O}_{11}$ & Molecular weight & $448.38 \mathrm{~g} / \mathrm{mol}$ \\
\hline & & & $\log P$ & 1.60 \\
\hline & & & H-bond donor & 7 \\
\hline & & & H-bond acceptor & 11 \\
\hline & & & Molar refractivity & 109.00 \\
\hline & & & Number of rotatable bonds & 3 \\
\hline & & & Violations & 2 \\
\hline \multirow[t]{7}{*}{15} & Salannolide & $\mathrm{C}_{34} \mathrm{H}_{44} \mathrm{O}_{11}$ & Molecular weight & $628.71 \mathrm{~g} / \mathrm{mol}$ \\
\hline & & & $\log P$ & 3.65 \\
\hline & & & H-bond donor & 1 \\
\hline & & & H-bond acceptor & 11 \\
\hline & & & Molar refractivity & 159.14 \\
\hline & & & Number of rotatable bonds & 9 \\
\hline & & & Violations & 3 \\
\hline \multirow[t]{7}{*}{16} & Vepnin & $\mathrm{C}_{28} \mathrm{H}_{36} \mathrm{O}_{5}$ & Molecular weight & $452.58 \mathrm{~g} / \mathrm{mol}$ \\
\hline & & & $\log P$ & 3.50 \\
\hline & & & $\mathrm{H}$-bond donor & 0 \\
\hline & & & H-bond acceptor & 5 \\
\hline & & & Molar refractivity & 124.72 \\
\hline & & & Number of rotatable bonds & 3 \\
\hline & & & Violations & 0 \\
\hline \multirow[t]{7}{*}{17} & Saquinavir & $\mathrm{C}_{38} \mathrm{H}_{50} \mathrm{~N}_{6} \mathrm{O}_{5}$ & Molecular weight & $670.84 \mathrm{~g} / \mathrm{mol}$ \\
\hline & & & $\log P$ & 3.66 \\
\hline & & & $\mathrm{H}$-bond donor & 5 \\
\hline & & & H-bond acceptor & 7 \\
\hline & & & Molar refractivity & 192.87 \\
\hline & & & Number of rotatable bonds & 16 \\
\hline & & & Violations & 2 \\
\hline \multirow[t]{7}{*}{18} & Nelfinavir & $\mathrm{C}_{32} \mathrm{H}_{45} \mathrm{~N}_{3} \mathrm{O}_{4} \mathrm{~S}$ & Molecular weight & $567.78 \mathrm{~g} / \mathrm{mol}$ \\
\hline & & & $\log P$ & 3.87 \\
\hline & & & $\mathrm{H}$-bond donor & 4 \\
\hline & & & H-bond acceptor & 5 \\
\hline & & & Molar refractivity & 166.17 \\
\hline & & & Number of rotatable bonds & 12 \\
\hline & & & Violations & 2 \\
\hline
\end{tabular}

The ligands for which the active compound present in Azadirachta indica were downloaded from Dr. Duke's Phytochemical and Ethnobotanical Databases (https://phytochem.nal.usda.gov/phytochem/search/list) The ligands present in the study were Azadirachtanin, Azadirachtol, Azadiradione, Betasitosterol, Epiazadiradione, Epoxyazadiradione, Kaempferol, Meldenin, Myricetin, Nimbaflavone, Nimbinene, Nimbione, Nimbocinolide, Quercitrin, Salannolide, and Vepnin. The threedimensional structures of the selected ligands from Azadirachta indica were obtained from PubChem (https://pubchem.ncbi.nlm.nih.gov/) in. sdf format. The properties of ligand molecules chosen for the study were listed in table 1. Anti-HIV drugs, Saquinavir, and Nelfinavir were used as positive control.

\section{Molecular docking}

The protease files were prepared for, COVID-19 6LU7 protease, 6Y2E protease, and 2GTB separately using Autodock 4.2. The macromolecule was prepared using ' $A$ ' chain of the protease, the water molecule was deleted, polar hydrogen atoms and charges were added. The file was saved in the. PDBQT format for further analysis. The grid box was used to obtain the $\mathrm{X}, \mathrm{Y}$, and $\mathrm{Z}$ coordinates. The ligand files in the. Mol 2 format was converted to the. PDBQT format by Open Babel after detecting the torsion root.

Using the protease. PDBQT file, ligand. PDBQT file and the $\mathrm{X}, \mathrm{Y}$, and $\mathrm{Z}$ coordinates, binding affinity was calculated using Lamarckian genetic algorithms by AutoDock 4.2. The conformations were played ranked by energy. The hydrogen bonds were viewed and the complex was saved in pdbqt format and then converted to. pdb format. The 3D structure of the protease-ligand complex interaction was visualized using PyMOL, and the 2D structure of the molecular interaction was visualized using the Biovia Discovery Studio 2020 Client. 


\section{RESULTS AND DISCUSSION}

Coronaviruses (CoVs) represented a major group of viruses, mostly affecting human beings through zoonotic transmission [13]. In the past two decades, this was the third occurrence of the emergence of a new coronavirus, after severe acute respiratory syndrome (SARS) in 2003 and Middle East respiratory syndrome coronavirus (MERSCoV) in 2012 [14, 15].

2GTB was the main protease found in the coronavirus associated with the severe acute respiratory syndrome (SARS), which could be retrieved in PDB and was recommended to be a potential drug target for 2019nCov and it shared $96 \%$ similarity with that of SARS [16]. 6Y2E and 6LU7 were the main protease found in Coronavirus and their structures were available in PDB. Ligands and anti-HIV compounds had been selected based on adherence to Lipinski's rule of five. The selected ligands that had 2 or less than 2 violations of Lipinski's rule were used in molecular docking experiments with the target proteins (6LU7 protease, 6Y2E protease, and 2GTB). Azadirachtanin, Azadirachtol, and Salannolide were omitted because of the violation of Lipinski's rule. The drug scanning outcomes (table 1) showed that 13 bioactive compounds and 2 positive controls used in this study were accepted by Lipinski's rule of five. Table 2,3 , and 4 showed the molecular docking analysis results of bioactive compounds against 6Y2E, 6LU7, and 2GTB, respectively including binding energy/Gibbs Energy, inhibition constant, intermolecular energy, torsional energy and internal energy. Fig. 1, 2 , and 3 showed 3D visualization of binding sites of various bioactive compounds from Azadirachta indica to the active sites of coronavirus protease 6Y2E, 6LU7, and 2 GTB.

Table 2: Molecular docking analysis of bioactive molecules from Azadirachta indica against 6Y2E

\begin{tabular}{|c|c|c|c|c|c|c|}
\hline S. No. & Name of the ligand & $\begin{array}{l}\text { Binding energy } \\
\text { (Kcal/mol) }\end{array}$ & $\begin{array}{l}\text { Inhibition } \\
\text { constant }\end{array}$ & Intermolecular energy & $\begin{array}{l}\text { Torsional } \\
\text { energy }\end{array}$ & $\begin{array}{l}\text { Internal } \\
\text { energy }\end{array}$ \\
\hline 1 & Azadiradione & -7.32 & 4.34 & -8.21 & 0.89 & -1.17 \\
\hline 2 & Beta-sitosterol & -6.63 & 13.76 & -8.72 & 2.09 & -1.13 \\
\hline 3 & Epiazadiradione & -7.52 & 3.06 & -8.42 & 0.89 & -1.3 \\
\hline 4 & Epoxyazadiradione & -5.27 & 136.58 & -6.17 & 0.89 & -1.22 \\
\hline 5 & Kaempferol & -4.54 & 472.42 & -6.03 & 1.49 & -1.36 \\
\hline 6 & Meldenin & -6.07 & 35.26 & -7.27 & 1.19 & -1.51 \\
\hline 7 & Myricetin & -4.19 & 851.61 & -6.28 & 2.09 & -2.03 \\
\hline 8 & Nimbaflavone & -5.02 & 208.13 & -7.41 & 2.39 & -2.54 \\
\hline 9 & Nimbinene & -5.58 & 80.63 & -7.37 & 1.79 & -2.09 \\
\hline 10 & Nimbione & -6.23 & 27.13 & -6.53 & 0.3 & 0.05 \\
\hline 11 & Nimbocinolide & -4.71 & 351.27 & -7.4 & 2.68 & -4.3 \\
\hline 12 & Quercitrin & -3.72 & 1890 & -6.7 & 2.98 & -4.03 \\
\hline 13 & Vepnin & -6.4 & 20.19 & -7.3 & 0.89 & -1.04 \\
\hline 14 & Saquinavir & -7.14 & 5.87 & -10.72 & 3.58 & 39.33 \\
\hline 15 & Nelfinavir & -4.67 & 374.41 & -8.25 & 3.58 & -2.94 \\
\hline
\end{tabular}

Out of 13 compounds evaluated from Azadirachta indica the binding energies lesser than the upper threshold $(-6 \mathrm{Kcal} / \mathrm{mol})$ were generally regarded as a cut-off in ligand binding studies $[17,18]$. The binding affinity for protease 6Y2E ranged between-3.72 (Quercitrin) to-7.52 (Epiazadiradione). The binding affinities for protease 6Y2E were -7.32,-6.63,-6.07,-6.23, and -6.4 for Azadiradione, Beta-sitosterol, Meldenin, Nimbione, and Vepnin respectively. The binding energy of Saquinavir was-6.89. When comparing the values of binding energies, Epiazadiradione and Azadiradione had more binding energy than Saquinavir.
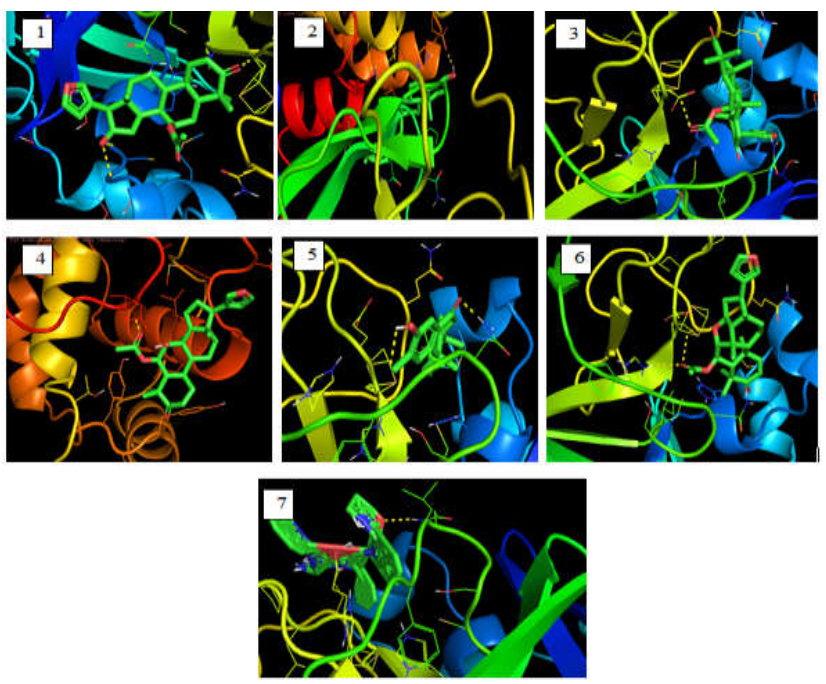

Fig. 1: 3D Visualization of docking analysis of 6Y2E protease binding with 1. Azadiradione 2. Beta-sitosterol 3. Epiazadiradione 4. Meldenin 5. Nimbione 6. Vepnin 7. Saquinavir. The yellow dots represent hydrogen bonds

Among the thirteen compounds evaluated from Azadirachta indica, the binding energies more than the upper threshold limit, of$6 \mathrm{Kcal} / \mathrm{mol}$ were only three. The binding affinity for protease $6 \mathrm{LU} 7$ ranged between-2.84 (Quercitrin) to-6.79 (Vepnin). The binding affinities for protease 6LU7 were-6.14, and-6.48 for Azadiradione, and Nimbione respectively. The binding energy of Saquinavir was6.49. The binding affinities of these three compounds were reasonably compared well with that of Saquinavir. 
Table 3: Molecular docking analysis of bioactive molecules from Azadirachta indica against 6LU7

\begin{tabular}{|c|c|c|c|c|c|c|}
\hline S. No. & Name of the ligand & $\begin{array}{l}\text { Binding } \\
\text { energy }\end{array}$ & $\begin{array}{l}\text { Inhibition } \\
\text { constant }\end{array}$ & Intermolecular energy & $\begin{array}{l}\text { Torsional } \\
\text { energy }\end{array}$ & $\begin{array}{l}\text { Internal } \\
\text { energy }\end{array}$ \\
\hline 1 & Azadiradione & -6.14 & 31.51 & -7.04 & 0.89 & -1.27 \\
\hline 2 & Beta-sitosterol & -4.94 & 238.75 & -7.03 & 2.09 & -1.65 \\
\hline 3 & Epiazadiradione & -5.92 & 46.01 & -6.81 & 0.89 & -1.34 \\
\hline 4 & Epoxyazadiradione & -5.51 & 90.85 & -6.41 & 0.89 & -1.15 \\
\hline 5 & Kaempferol & -5.27 & 137.8 & -6.76 & 1.49 & -1.4 \\
\hline 6 & Meldenin & -5.05 & 197.21 & -6.25 & 1.19 & -2.12 \\
\hline 7 & Myricetin & -5.08 & 189.67 & -7.17 & 2.09 & -2.17 \\
\hline 8 & Nimbaflavone & -4.04 & 1100 & -6.42 & 2.39 & -1.94 \\
\hline 9 & Nimbinene & -5.2 & 155.19 & -6.99 & 1.79 & -2.02 \\
\hline 10 & Nimbione & -6.48 & 17.84 & -6.78 & 0.3 & 0.04 \\
\hline 11 & Nimbocinolide & -4.99 & 220.62 & -7.67 & 2.68 & -4.79 \\
\hline 12 & Quercitrin & -2.84 & 8.32 & -5.82 & 2.98 & -4.81 \\
\hline 13 & Vepnin & -6.79 & 10.49 & -7.69 & 0.89 & -0.85 \\
\hline 14 & Saquinavir & -6.49 & 17.36 & -10.67 & 3.58 & 38.13 \\
\hline 15 & Nelfinavir & -3.22 & 4.36 & -6.8 & 3.58 & -3.48 \\
\hline
\end{tabular}
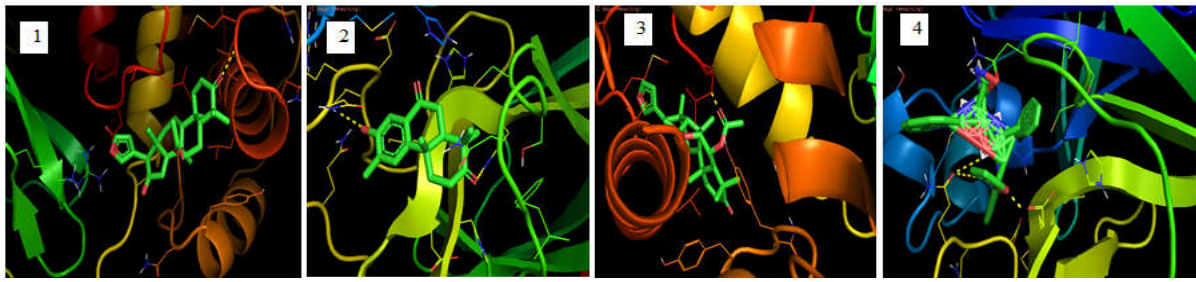

Fig. 2: 3D Visualization of docking analysis of 6 LU7 protease binding with 1 . Azadiradione 2. Nimbione 3. Vepnin 4. Saquinavir. The yellow dots represent hydrogen bonds

Table 4: Molecular docking analysis of bioactive molecules from Azadirachta indica against 2GTB

\begin{tabular}{|c|c|c|c|c|c|c|}
\hline S. No. & Name of the ligand & $\begin{array}{l}\text { Binding energy } \\
\text { (Kcal/mol) }\end{array}$ & $\begin{array}{l}\text { Inhibition } \\
\text { constant }\end{array}$ & $\begin{array}{l}\text { Intermolecular } \\
\text { energy }\end{array}$ & Torsional energy & $\begin{array}{l}\text { Internal } \\
\text { energy }\end{array}$ \\
\hline 1 & Azadiradione & -6.96 & 7.88 & -7.86 & 0.89 & -1.2 \\
\hline 2 & Beta-sitosterol & -6.63 & 22.94 & -8.42 & 2.09 & -1.24 \\
\hline 3 & Epiazadiradione & -7.13 & 5.9 & -8.03 & 0.89 & -1.31 \\
\hline 4 & Epoxyazadiradione & -6.69 & 12.44 & -7.59 & 0.89 & -1.09 \\
\hline 5 & Kaempferol & -5.22 & 149.3 & -6.71 & 1.49 & -1.38 \\
\hline 6 & Meldenin & -6.44 & 19.0 & -7.63 & 1.19 & -1.68 \\
\hline 7 & Myricetin & -5.06 & 194.42 & -7.15 & 2.09 & -2.02 \\
\hline 8 & Nimbaflavone & -5.93 & 44.69 & -8.32 & 2.39 & -1.96 \\
\hline 9 & Nimbinene & -4.68 & 370.49 & -6.47 & 1.79 & -2.04 \\
\hline 10 & Nimbione & -6.66 & 13.06 & -6.96 & 0.3 & 0.04 \\
\hline 11 & Nimbocinolide & -5.3 & 129.63 & -7.99 & 2.68 & -4.28 \\
\hline 12 & Quercitrin & -5.63 & 75.17 & -8.61 & 2.98 & -4.09 \\
\hline 13 & Vepnin & -7.11 & 6.15 & -8.0 & 0.89 & -0.86 \\
\hline 14 & Saquinavir & -6.89 & 8.92 & -10.47 & 3.58 & 38.02 \\
\hline 15 & Nelfinavir & -5.42 & 106.48 & -9.0 & 3.58 & -3.49 \\
\hline
\end{tabular}
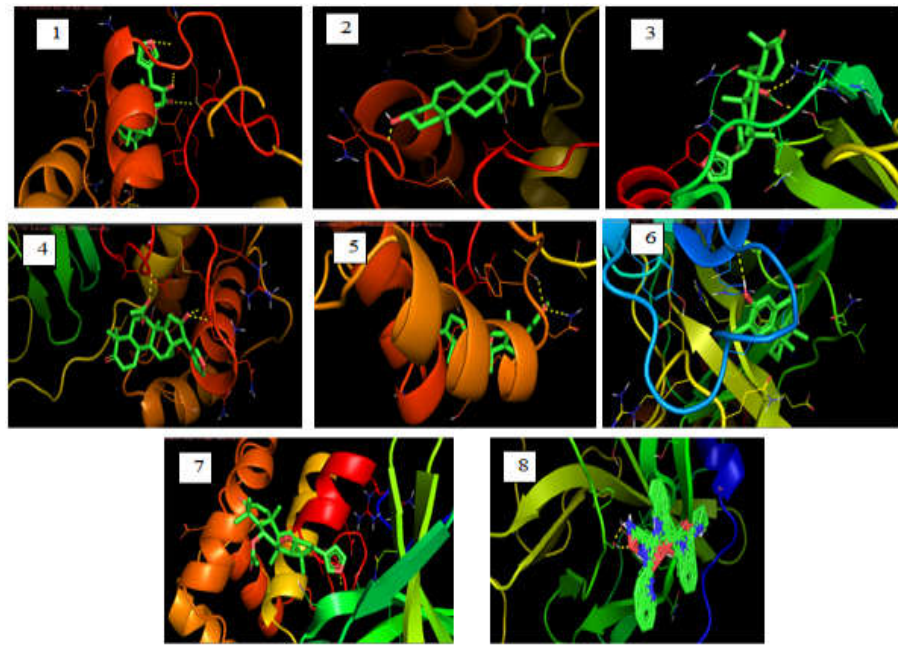

Fig. 3: 3D Visualization of docking analysis of 2GTB protease binding with 1. Azadiradione 2. Beta-sitosterol 3. Epiazadiradione 4. Epoxyazadiradione 5. Meldenin 6. Nimbione 7. Vepnin 8. Saquinavir. The yellow dots represent hydrogen bonds 
Out of 13 compounds evaluated from Azadirachta indica the binding energies more than the upper threshold limit, of- $6 \mathrm{Kcal} / \mathrm{mol}$ were selected. The binding affinity for protease 2GTB ranged between4.68 (Nimbinene) to-7.13 (Epiazadiradione). The binding affinities for protease 2GTB were-6.96,-7.13,-6.69,-6.44,-6.66,-5.63,-7.11,-6.89 for Azadiradione, Beta-sitosterol, Epoxyazadiradione, Meldenin, Nimbione, and Vepnin respectively. The binding energy of Saquinavir was-6.89. The binding affinities of these compounds were reasonably compared well with that of Saquinavir. Nelfinavir showed binding energies lesser than the threshold limit with all the 3 proteases.

Fig. 4 showed 2D visualization of binding sites of various bioactive compounds from Azadirachta indica to the active sites of coronavirus proteases 6Y2E, 6LU7, and 2GTB. The 3D and 2D visualization results clearly indicated that the ligand molecules bind to the active site of the coronavirus proteases and therefore, it could be expected to inhibit the enzyme activity and stopped the replication of the virus. Bioactive compounds (ligands)
Azadiradione, Beta-sitosterol, Epoxyazadiradione, Meldenin, Nimbione, and Vepnin responded well against the Coronavirus proteases 6Y2E, 6LU7 and 2 GTB.

Azadirachtin and Epoxyazadiradione had significantly higher or similar binding efficacy against their SARS-CoV-2 targets 6VSB (surface spike glycoprotein) 6Y84 (main Protease) and 6M71 (RNA dependent RNA polymerase) when compared to Lopinavir/Ritonavir and Remdesivir [19]. Shanmuga Subramanian in 2020 showed that the binding energies obtained from the docking of 6LU7 with Meliacinanhydride, Nimocinol, Isomeldenin, Nimbolide, Zafaral, Nimbandiol, Nimbin, Nimbinene, Desacetylnimbin were-14.3,-12.4,-12.3,-12.2,-11.9,-11.8,-11.7,-11.7,$11.4 \mathrm{kcal} / \mathrm{mol}$ respectively. These compounds showed better binding energies when compared with Remdesivir and HydroxyCholoroquine [20]. Apart from these bioactive compounds, neem leaves contain other compounds like Zinc, Vitamin A, Vitamin B1, Vitamin B2, Vitamin B6, Vitamin C, Vitamin E, etc. which may boost immunity [21].
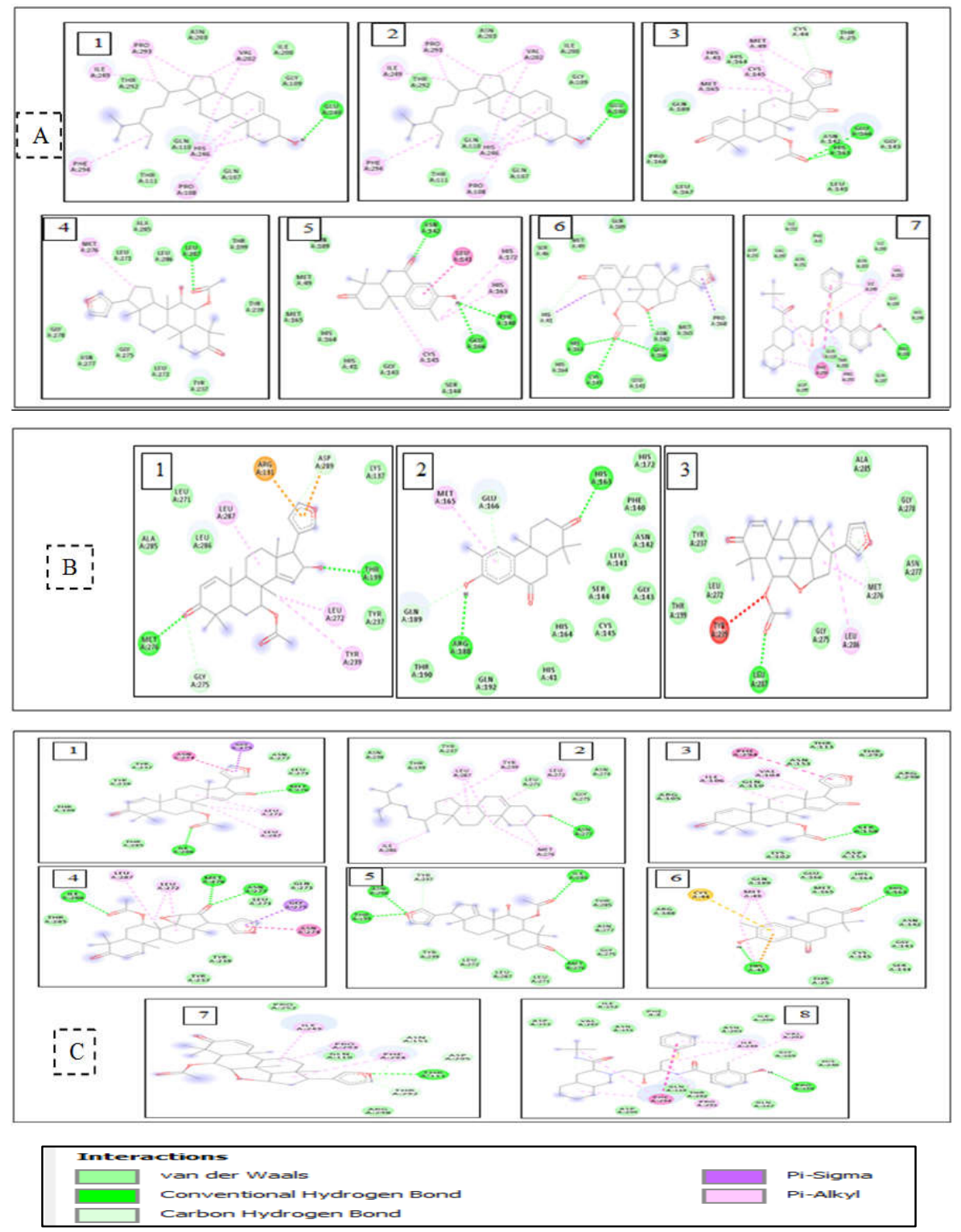

Fig. 4: 2D Visualization of molecular interaction with A) 6Y2E B) 6LU7 C) 2GTB with A1. Azadiradione, A2. Beta-sitosterol, A3.

Epiazadiradione, A4. Meldenin, A5. Nimbione, A6. Vepnin, A7. Saquinavir, B1. Azadiradione, B2. Nimbione, B3. Vepnin, C1. Azadiradione C2. Beta-sitosterol, C3. Epiazadiradione, C4. Epoxyazadiradione, C5. Meldenin, C6. Nimbione, C7. Vepnin, C8. Saquinavir 


\section{CONCLUSION}

The use of natural products for the disease cure and prevention is increasing all over the world because of its lesser side effects. Azadirachta indica is a common tree that will be present in all the houses and its leaves, bark, trunk; seeds had been already known for its antiviral and antibacterial properties around the world. The present study also proved that the bioactive compounds like Azadiradione, Beta-sitosterol, Epoxyazadiradione, Meldenin, Nimbione, and Vepnin from Azadirachta indica had antiviral property against Coronavirus. However, further in vitro and in vivo tests are required to assess the compounds from the tree as clinical drugs.

\section{FUNDING}

Nil

\section{AUTHORS CONTRIBUTIONS}

All the authors have contributed equally.

\section{CONFLICTS OF INTERESTS}

Author declares that there are no conflicts of interest.

\section{REFERENCES}

1. Shivanshu S. Coronavirus (COVID-19): a pandemic disorder. Int J Pharm Pharm Res 2020;18:132-46.

2. Ahbanathul Missriya MA, Suhail Hassan. Assess the awareness and attitude regarding the prevention of Coronavirus disease in 2019. Asian J Pharm Clin Res 2020;13:95-8.

3. Wang C, Horby PW, Hayden FG, Gao GF. A novel coronavirus outbreak of global health concern. Lancet 2020;395:470-3.

4. Rohan RN, Rameshwar SC, Jaya PA, Sachin DS. The molecular docking study of potential drug candidates showing anti-covid19 activity by exploring of therapeutic targets of SARS-CoV-2. EJMO 2020;4:185-95.

5. Wu C, Liu Y, Yang Y, Zhang P, Zhong W. Analysis of therapeutic targets for SARS-CoV-2 and discovery of potential drugs by computational methods. Acta Pharm Sin B 2020;10:766-88.

6. Ikita Pal, Shambaditya Goswami, Ravindra Pal Singh, Prashant Singh. A way to prevent the pandemic outbreak of nCOVID-19 in India. Asian J Pharm Clin Res 2020;13:39-40.

7. Bosch BJ, van der ZR, de Haan CA, Rottier PJ. The coronavirus spike protein is a class I virus fusion protein: structural and functional characterization of the fusion core complex. J Virol 2003;77:8801-11.

8. Siti K, Hendra K, Rizki A, Suhartati S, Soetjipto S. Potential inhibitor of covid-19 main protease (Mpro) from several medicinal plant compounds by molecular docking study. Preprints 2020;1-14. DOI:10.20944/preprints202003.0226.v1

9. Alzohairy MA. Therapeutics role of Azadirachta indica (Neem) and their active constituents in disease prevention and treatment. Evid Based Complement Alternat Med 2016;7382506. https://doi.org/10.1155/2016/7382506

10. Ahmad A, Javed MR, Rao AQ. Designing and screening of universal drug from neem (Azadirachta indica) and standard drug chemicals against influenza virus nucleoprotein. BMC Complement Altern Med 2016;16:519.

11. Christopher AL, Franco L, Beryl WD, Paul JF. Experimental and computational approaches to estimate solubility and permeability in drug discovery and development settings. Adv Drug Delivery Rev 1997;23:3-25

12. Gimenez B, Santos M, Marcio F, Fernandes J. Evaluation of blockbuster drugs under the Rule-of-five. Die Pharmazie 2010;65:148-52.

13. Chatterjee P, Nagi N, Agarwal A, Das B. The 2019 novel coronavirus disease (COVID-19) pandemic: a review of the current evidence. Indian J Med Res 2020;151:147-59.

14. Ramadan N, Shaib H. Middle East respiratory syndrome coronavirus (MERS-CoV): a review. Germs 2019;9:35-42.

15. Zhong NS, Zheng $\mathrm{BJ}, \mathrm{Li} \mathrm{YM}$, Poon, Xie $\mathrm{ZH}$, Chan $\mathrm{KH}$, et al. Epidemiology and cause of severe acute respiratory syndrome (SARS) in Guangdong, People's Republic of China, in February 2003. Lancet 2003;362:1353-8.

16. Zhijian X, Cheng $\mathrm{P}$, Yulong S, Zhengdan Z. Nelfinavir was predicted to be a potential inhibitor of 2019-nCov main protease by an integrative approach combining homology modelling, molecular docking and binding free energy calculation; 2020. p. 1201.

17. Shityakov S, Forster C. In silico predictive model to determine vector-mediated transport properties for the blood-brain barrier choline transporter. Adv Appl Bioinform Chem 2014;7:23.

18. Megha HS, Ram V, Uma SR. Molecular docking analysis of selected natural products from plants for inhibition of SARSCoV-2 main protease. Curr Sci 2020;118:1087-92.

19. Kumar AHS. Molecular docking of natural compounds from tulsi (Ocimum sanctum) and neem (Azadirachta indica) against SARS-CoV-2 protein targets. BEMS Reports 2020;6:11-13.

20. Shanmuga SS. Some compounds from neem leaves extract exhibit binding affinity as high as- $14.3 \mathrm{kcal} / \mathrm{mol}$ against COVID19 main protease (Mpro): a molecular docking study, research square; 2020. p. 1-10.

21. Garba S, Mungadi HU. Quantitative chemical compositions of neem leaf aqueous extracts. Int J Res Sci Innov 2019;6:114-9. 